\title{
Plunger Device
}

National Cancer Institute

\section{Source}

National Cancer Institute. Plunger Device. NCI Thesaurus. Code C50297.

A mechanical device designed to slide within a chamber to transfer a material. 